Article

\title{
Cigarette Smoking Is Associated with Increased Risk of Malignant Gliomas: A Nationwide Population-Based Cohort Study
}

\author{
Stephen Ahn ${ }^{1}$, Kyung-Do Han ${ }^{2}$, Yong-Moon Park ${ }^{3}$, Jung Min Bae ${ }^{4}$, Sang Uk Kim ${ }^{5}$, \\ Sin-Soo Jeun ${ }^{1}$ and Seung Ho Yang ${ }^{6, *(1)}$ \\ 1 Department of Neurosurgery, Seoul St. Mary's Hospital, College of Medicine, The Catholic University of \\ Korea, Seoul 06591, Korea; nsstp@catholic.ac.kr (S.A.); ssjeun@catholic.ac.kr (S.-S.J.) \\ 2 Statistics and Actuarial Science, Soongsil University, Seoul 06978, Korea; hkd917@naver.com \\ 3 Epidemiology Branch, National Institute of Environmental Health Sciences, National Institutes of Health, \\ Research Triangle Park, NC 27709, USA; markparkjecos@gmail.com \\ 4 Department of Dermatology, St. Vincent's Hospital College of Medicine, The Catholic University of Korea, \\ Seoul 16247, Korea; jminbae@gmail.com \\ 5 MyoungJi St. Mary's Hospital, Seoul 07417, Korea; tkddnr79@catholic.ac.kr \\ 6 Department of Neurosurgery, St. Vincent's Hospital, College of Medicine, The Catholic University of Korea, \\ Suwon 16247, Korea \\ * Correspondence: 72ysh@catholic.ac.kr; Tel.: +82-31-249-8303; Fax: +82-31-245-5208
}

Received: 7 April 2020; Accepted: 22 May 2020; Published: 25 May 2020

\begin{abstract}
The association between cigarette smoking and the risk of developing malignant glioma (MG) remains unclear. We aimed to evaluate this potential association in a large general population, using a well-established and validated longitudinal nationwide database. Using data from the Korean National Health Insurance System cohort, 9,811,768 people over 20 years old without any cancer history in 2009 were followed until the end of 2017. We documented 6100 MG cases (ICD-10 code C71) during the median follow-up period of 7.31 years. Current smokers had a higher risk of developing MG (HR = 1.22, CI: 1.13-1.32) compared with never-smokers, after adjusting for confounders. This association was stronger for those who smoked $\geq 20$ cigarettes daily (HR $=1.50, \mathrm{CI}$ : 1.36-1.64). Furthermore, having 30 or more pack-years of smoking over the course of one's lifetime was associated with an increased risk of developing MG in a dose-dependent manner, compared with never-smokers (HR = 1.31, CI: 1.16-1.48 for 30-39 pack-years of smoking; $\mathrm{HR}=1.36$, CI: $1.17-1.59$ for 40-49 pack-years of smoking; $\mathrm{HR}=1.68$; CI: $1.44-1.95$ for $\geq 50$ pack-years of smoking). These results suggest that cigarette smoking may be associated with developing MG. Further prospective studies could help elucidate this association.
\end{abstract}

Keywords: glioma; smoking; risk factors; epidemiologic studies; population

\section{Introduction}

Malignant gliomas (MG) are the most common primary brain tumor in adults, with incidence rates of 5-10 per 100,000 person-years, and they usually have a devastating prognosis [1-4]. MG are generally classified into five main subtypes according to the World Health Organization (WHO) classification published in 2016 (glioblastoma, IDH-wild type; glioblastoma, IDH-mutant; astrocytoma, IDH-wild type; astrocytoma IDH-mutant; and oligodendroglioma, IDH-mutant and 1p19q co-deleted). In glioblastoma cases, which are the most common subtype and account for more than $70 \%$ of all gliomas, median survival is less than 1.5 years; median survival time of the other subtypes varies from 2 years to more than 10 years [4-6]. 
Cigarette smoking has already been established as one of the most significant risk factors for numerous cancers $[7,8]$. Clinical and animal studies have provided strong evidence that current smoking status is associated with increased risk of developing various cancers $[9,10]$. Moreover, risk increases proportionately to the cumulative lifetime amount of smoking in a dose-dependent manner [11,12].

While multifactorial factors, including environmental and genetic factors, are suggested to be associated with MG, the only proven risk factor is exposure to ionized radiation [13,14]. Etiology and susceptibility factors for MG remain largely unknown [13,14].

Recent biological findings have suggested a potential association between cigarette smoking and the risk of developing MG $[15,16]$. A number of cohort studies, case-control studies, and meta-analyses have explored this association epidemiologically, but results from these studies are inconclusive [17-30]. Among the studies that found an association were some limitations: two showed only positive associations in female populations [28,29], and a recent case-control study that included 4566 gliomas cases - the largest study to date-only found associations between cigarette smoking and death from gliomas, but not with risk for MG [19].

In this study, we evaluated the potential association between cigarette smoking and MG risk in a large sample, using a nationwide population database of Koreans. The Korea National Health Insurance Service (NHIS), which is a mandatory health insurance system covering 97\% of all Koreans, has recently established a patient cohort. A number of previous studies have generated powerful results for identifying cancer risks by using this large nationwide database [31-33].

\section{Results}

\subsection{Characteristics of the Study Population}

Among the 9,811,768 patients in our study population, 5,820,623 (59.32\%) were never-smokers, $1,400,124(14.27 \%)$ were former smokers, and 2,591,021 (26.41\%) were current smokers. Never-smokers and former smokers were significantly older than current smokers $(p<0.001)$. Being male and related factors such as height, weight, waist circumference, and heavy drinking were significantly associated with former or current smokers $(p<0.001)$. Detailed characteristics of populations were described in Table 1.

Table 1. Baseline characteristics of the study population according to smoking status.

\begin{tabular}{|c|c|c|c|c|}
\hline \multirow{2}{*}{ Characteristic Title } & Never-Smokers & Former Smokers & Current Smokers & \multirow{2}{*}{$p$-Value } \\
\hline & $n=5,820,623(59.32)$ & $n=1,400,124(14.27)$ & $n=2,591,021(26.41)$ & \\
\hline Mean age, years ${ }^{a}$ & $48.47 \pm 14.55$ & $48.67 \pm 13.03$ & $42.66 \pm 12.49$ & $<0.001$ \\
\hline $20-39, n(\%)$ & $1,576,423(27.08)$ & $364,065(26.00)$ & $1,173,409(45.29)$ & \\
\hline $40-64, n(\%)$ & $3,336,188(57.32)$ & $854,543(61.03)$ & $1,253,281(48.37)$ & \\
\hline$\geq 65, n(\%)$ & 908,012 (15.6) & $181,516(12.96)$ & $164,331(6.34)$ & \\
\hline Male & $1,634,168(28.08)$ & $1,316,955(94.06)$ & $2,437,271(94.07)$ & $<0.001$ \\
\hline Height, $\mathrm{cm}^{\mathrm{a}}$ & $160.03 \pm 8.55$ & $169.01 \pm 6.71$ & $169.98 \pm 7.01$ & $<0.001$ \\
\hline Weight, $\mathrm{cm}^{\mathrm{a}}$ & $60.26 \pm 10.52$ & $69.62 \pm 10.22$ & $69.25 \pm 11.33$ & $<0.001$ \\
\hline Waist circumference, $\mathrm{cm}^{\mathrm{a}}$ & $78.27 \pm 9.16$ & $83.95 \pm 7.87$ & $82.61 \pm 8.24$ & $<0.001$ \\
\hline BMI, $\mathrm{kg} / \mathrm{m}^{2} \mathrm{a}$ & $23.47 \pm 3.25$ & $24.32 \pm 2.91$ & $23.9 \pm 3.21$ & $<0.001$ \\
\hline Urban residence, $n(\%)$ & $3,123,516(53.66)$ & $739,082(52.79)$ & $1,434,412(55.36)$ & $<0.001$ \\
\hline Heavy drinker ${ }^{\mathrm{b}}, n(\%)$ & $117,516(2.02)$ & $161,722(11.55)$ & $399,344(15.41)$ & $<0.001$ \\
\hline Regular exercise ${ }^{c}, n(\%)$ & $2,705,616(46.48)$ & $905,008(64.64)$ & $1,436,112(55.43)$ & $<0.001$ \\
\hline Diabetes mellitus, $n(\%)$ & $469,259(8.06)$ & $154,318(11.02)$ & $221,970(8.57)$ & $<0.001$ \\
\hline Hypertension, $n$ (\%) & $1,507,526(25.9)$ & $440,210(31.44)$ & $560,252(21.62)$ & $<0.001$ \\
\hline Dyslipidemia, $n(\%)$ & $1,102,507(18.94)$ & $281,650(20.12)$ & $403,142(15.56)$ & $<0.001$ \\
\hline Previous ischemic heart disease, $n(\%)$ & $112,688(3.12)$ & $45,101(4.78)$ & $35,888(2.19)$ & $<0.001$ \\
\hline Previous cerebral stroke, $n(\%)$ & $50,943(1.41)$ & $26,027(2.76)$ & $22,864(1.39)$ & $<0.001$ \\
\hline Mean amounts of cigarette smoked per day & 0 & $16.0 \pm 9.1$ & $16.0 \pm 7.3$ & \\
\hline Mean smoking duration & 0 & $16.2 \pm 10.6$ & $18.8 \pm 11.1$ & \\
\hline Mean pack-years & 0 & $14.6 \pm 14.6$ & $16.0 \pm 13.2$ & \\
\hline Hemoglobin, g/dL & $13.33 \pm 1.49$ & $14.69 \pm 1.25$ & $14.97 \pm 1.26$ & $<0.001$ \\
\hline
\end{tabular}

BMI, body-mass index; BP, blood pressure; $n$, number; ${ }^{a}$ Mean \pm standard deviation; ${ }^{\mathrm{b}}$ Defined as a person who consumed $>30 \mathrm{~g}$ of alcohol per day on average; ${ }^{\mathrm{c}}$ Defined as intensive physical activity of $>3$ days per week or moderate physical activity of $>5$ days per a week. 


\subsection{Incidence Rates and Risk of Developing MG According to Smoking Status}

A total of 6100 MGs developed during the median follow-up period of 7.31 years and 71,280,380 person-years. MG incidence rates per 100,000 person-years were 8.80 in never-smokers, 8.91 in former smokers, and 7.81 in current smokers (Table 2). Because the mean age of current smokers was significantly younger than that of never and former smokers, and age is one of the most significant risk factors for MG, we analyzed MG incidence rates according to age by decade. After analyzing, we found that current smokers showed significantly increased incidence rates of MG than never and former smokers, in populations 50 years and older (Table S1). In adjusted models to correct for age and other possible confounding factors, current smokers showed a significantly higher risk of developing MG than former never-smokers (HR 1.19, CI 1.10-1.28 and HR 1.22, CI 1.13-1.32 in model 1 and 2, respectively) (Table 2).

Table 2. Incidence rates and risk of malignant gliomas, according to smoking status.

\begin{tabular}{|c|c|c|c|c|c|c|c|}
\hline $\begin{array}{l}\text { Smoking } \\
\text { Status }\end{array}$ & Total, $n$ & $\begin{array}{c}\text { MG } \\
\text { Events, } n\end{array}$ & $\begin{array}{l}\text { Person- } \\
\text { Years }\end{array}$ & $\begin{array}{c}\text { MG } \\
\text { Incidence Rate * }\end{array}$ & $\begin{array}{c}\text { Crude HR } \\
(95 \% \mathrm{CI})\end{array}$ & $\begin{array}{c}{ }^{a} \text { Model } 1 \text { HR } \\
(95 \% \text { CI })\end{array}$ & $\begin{array}{c}\text { b Model } 2 \text { HR } \\
(95 \% \text { CI })\end{array}$ \\
\hline Never-smokers & $5,820,623$ & 3733 & $42,405,897$ & 8.80 & 1 (reference) & 1 (reference) & 1 (reference) \\
\hline $\begin{array}{l}\text { Current } \\
\text { smokers }\end{array}$ & $2,591,021$ & 1463 & $18,731,140$ & 7.81 & $\begin{array}{c}0.89 \\
(0.84-0.94)\end{array}$ & $\begin{array}{c}1.19 \\
(1.10-1.28)\end{array}$ & $\begin{array}{c}1.22 \\
(1.13-1.32)\end{array}$ \\
\hline
\end{tabular}

CI, confidence interval; HR, hazard ratio; MG, malignant glioma; $n$, number; ${ }^{*}$ per 100,000 person-years; ${ }^{a}$ Model 1: adjusted for age and sex; ${ }^{b}$ Model 2: adjusted for model 1 plus alcohol consumption, body-mass index, income level, and exercise level.

\subsection{Risk of Developing MG According to Smoking Amount and Duration}

We analyzed the association between MG risk and per-day number of cigarettes smoked (Table 3). Among current smokers, there was a significantly higher risk of developing MG in people who smoked $>20$ cigarettes per day compared with never-smokers (HR 1.44, CI 1.32-1.58 \& HR 1.50, CI 1.36-1.64, in model 1 and 2, respectively). Additionally, former smokers who used to smoke $>20$ cigarettes per day showed an increased risk of developing MG, relative to never-smokers (HR 1.15, CI 1.00-1.30 in model 2). Former smokers who smoked $<20$ cigarettes per day showed no significant differences in MG risk compared with never-smokers.

We also analyzed the associations between developing MG and smoking duration (Table 3). In model 2, current smokers had significantly increased risk of developing MG, regardless of smoking duration. Former smokers had no increased risk of developing MG compared with never-smokers, regardless of smoking duration.

Table 3. Risk of developing malignant glioma according to smoking amount and duration.

\begin{tabular}{|c|c|c|c|c|c|c|c|}
\hline Smoking Status & $\begin{array}{c}\text { Total } \\
\text { Number, } n \\
\text { (\% of } \\
\text { Proportion) }\end{array}$ & $\begin{array}{c}\text { MG } \\
\text { Events, } \\
n\end{array}$ & $\begin{array}{l}\text { Person- } \\
\text { Years }\end{array}$ & $\begin{array}{c}\text { MG } \\
\text { Incidence } \\
\text { Rate * }\end{array}$ & $\begin{array}{c}\text { Crude HR } \\
(95 \% \text { CI })\end{array}$ & $\begin{array}{c}{ }^{\text {a }} \text { Model } 1 \\
\text { HR } \\
(95 \% \text { CI })\end{array}$ & $\begin{array}{c}\text { b Model } 2 \\
\text { HR } \\
(95 \% \text { CI })\end{array}$ \\
\hline Never-smokers & $\begin{array}{c}5,820,623 \\
(59.3)\end{array}$ & 3,733 & $42,513,670$ & 8.80 & 1 (reference) & 1 (reference) & 1 (reference) \\
\hline \multicolumn{8}{|l|}{$\begin{array}{l}\text { Former smokers } \\
\text { Cigarettes } \\
\text { smoked per day }\end{array}$} \\
\hline$<10$ & $364,712(3.7)$ & 155 & $2,620,568$ & 5.72 & $\begin{array}{c}0.84 \\
(0.71-1.00)\end{array}$ & $\begin{array}{c}0.95 \\
(0.80-1.12)\end{array}$ & $\begin{array}{c}0.97 \\
(0.81-1.14)\end{array}$ \\
\hline $10-19$ & $818,051(8.3)$ & 467 & $5,949,887$ & 7.85 & $\begin{array}{c}0.88 \\
(0.78-0.99)\end{array}$ & $\begin{array}{c}0.92 \\
(0.83-1.03)\end{array}$ & $\begin{array}{c}0.94 \\
(0.85-1.05)\end{array}$ \\
\hline$\geq 20$ & $217,361(2.2)$ & 282 & $1,528,462$ & 18.45 & $\begin{array}{c}1.20 \\
(1.10-1.32)\end{array}$ & $\begin{array}{c}1.12 \\
(0.98-1.28)\end{array}$ & $\begin{array}{c}1.15 \\
(1.00-1.30)\end{array}$ \\
\hline $\begin{array}{c}\text { Smoking } \\
\text { duration (years) }\end{array}$ & & & & & & & \\
\hline
\end{tabular}


Table 3. Cont.

\begin{tabular}{|c|c|c|c|c|c|c|c|}
\hline Smoking Status & $\begin{array}{c}\text { Total } \\
\text { Number, } n \\
\text { (\% of } \\
\text { Proportion) }\end{array}$ & $\begin{array}{c}\text { MG } \\
\text { Events, } \\
n\end{array}$ & $\begin{array}{l}\text { Person- } \\
\text { Years }\end{array}$ & $\begin{array}{c}\text { MG } \\
\text { Incidence } \\
\text { Rate * }\end{array}$ & $\begin{array}{c}\text { Crude HR } \\
(95 \% \text { CI) }\end{array}$ & $\begin{array}{c}{ }^{\text {a }} \text { Model } 1 \\
\text { HR } \\
(95 \% \text { CI })\end{array}$ & $\begin{array}{c}\text { b Model } 2 \\
\text { HR } \\
(95 \% \mathrm{CI})\end{array}$ \\
\hline$<10$ & $251,965(2.6)$ & 136 & $1,832,908$ & 5.72 & $\begin{array}{c}0.66 \\
(0.56-0.78)\end{array}$ & $\begin{array}{c}0.91 \\
(0.77-1.09)\end{array}$ & $\begin{array}{c}0.93 \\
(0.78-1.11)\end{array}$ \\
\hline $10-29$ & $534,103(5.4)$ & 300 & $3,880,899$ & 7.85 & $\begin{array}{c}0.88 \\
(0.81-0.98)\end{array}$ & $\begin{array}{c}0.93 \\
(0.82-1.05)\end{array}$ & $\begin{array}{c}0.95 \\
(0.84-1.08)\end{array}$ \\
\hline$\geq 30$ & $614,056(6.3)$ & 468 & $4,429,536$ & 18.45 & $\begin{array}{c}2.10 \\
(1.86-2.37)\end{array}$ & $\begin{array}{c}1.05 \\
(0.94-1.17)\end{array}$ & $\begin{array}{c}1.07 \\
(0.96-1.19)\end{array}$ \\
\hline \multicolumn{8}{|l|}{$\begin{array}{l}\text { Current smokers } \\
\text { Cigarettes } \\
\text { smoked per day }\end{array}$} \\
\hline$<10$ & $426,590(4.3)$ & 129 & $3,051,709$ & 4.03 & $\begin{array}{c}0.97 \\
(0.84-1.12)\end{array}$ & $\begin{array}{c}1.02 \\
(0.85-1.23)\end{array}$ & $\begin{array}{c}1.05 \\
(0.87-1.26)\end{array}$ \\
\hline $10-19$ & $\begin{array}{c}1,631,714 \\
(16.6)\end{array}$ & 604 & $11,868,42$ & 5.09 & $\begin{array}{c}0.75 \\
(0.58-0.82)\end{array}$ & $\begin{array}{c}0.98 \\
(0.88-1.08)\end{array}$ & $\begin{array}{c}1.00 \\
(0.90-1.10)\end{array}$ \\
\hline$\geq 20$ & $532,717(5.4)$ & 730 & $3,747,653$ & 19.48 & $\begin{array}{c}0.99 \\
(0.92-1.08)\end{array}$ & $\begin{array}{c}1.45 \\
(1.32-1.59)\end{array}$ & $\begin{array}{c}1.50 \\
(1.37-1.65)\end{array}$ \\
\hline \multicolumn{8}{|l|}{$\begin{array}{c}\text { Smoking } \\
\text { duration (years) }\end{array}$} \\
\hline$<10$ & $323,511(3.3)$ & 199 & $2,331,871$ & 4.03 & $\begin{array}{c}0.47 \\
(0.40-0.56)\end{array}$ & $\begin{array}{c}1.21 \\
(1.04-1.40)\end{array}$ & $\begin{array}{c}1.25 \\
(1.07-1.44)\end{array}$ \\
\hline $10-29$ & $\begin{array}{c}1,089,332 \\
(11.1)\end{array}$ & 518 & $7,895,617$ & 5.09 & $\begin{array}{c}0.58 \\
(0.53-0.63)\end{array}$ & $\begin{array}{c}1.10 \\
(0.99-1.21)\end{array}$ & $\begin{array}{c}1.13 \\
(1.02-1.25)\end{array}$ \\
\hline$\geq 30$ & $\begin{array}{c}1,178,178 \\
(12.0)\end{array}$ & 746 & $8,503,651$ & 19.48 & $\begin{array}{c}2.22 \\
(2.05-2.40)\end{array}$ & $\begin{array}{c}1.26 \\
(1.15-1.38)\end{array}$ & $\begin{array}{c}1.29 \\
(1.18-1.42)\end{array}$ \\
\hline
\end{tabular}

CI, confidence interval; HR, hazard ratio; MG, malignant glioma; $n$, number, ${ }^{*}$ per 100,000 person-years, ${ }^{a}$ Model 1: adjusted for age and sex, ${ }^{\mathrm{b}}$ Model 2: adjusted for model 1 plus alcohol consumption, body-mass index, income level, and exercise level.

\subsection{MG Risk According to Cumulative Lifetime Amount of Smoking}

We found a significant dose-dependent association between cumulative lifetime amount of smoking and risk of developing MG (Figure 1a). People who ever smoked $>30$ pack-years in their lifetime had a significantly increased risk of developing MG compared with never-smokers (HR 1.31, CI 1.16-1.48). Among ever-smokers, the risk of developing MG increased in proportion to the cumulative amount of lifetime smoking: the highest risk of developing MG was among people who ever smoked $>50$ pack-years (HR 1.68, CI 1.44-1.95), followed by people who ever smoked 40-49 pack-years (HR 1.36, CI 1.17-1.59), and then by people who ever smoked 30-39 pack-years (HR 1.31, CI 1.16-1.48) (Figure 1b).

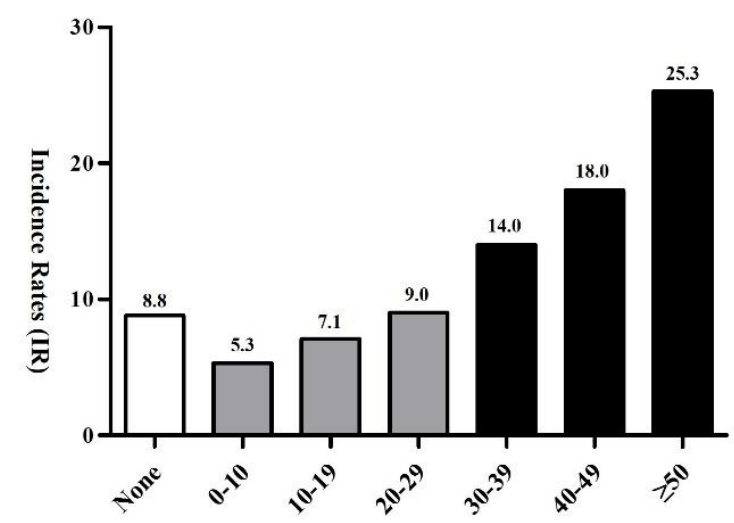

(a)

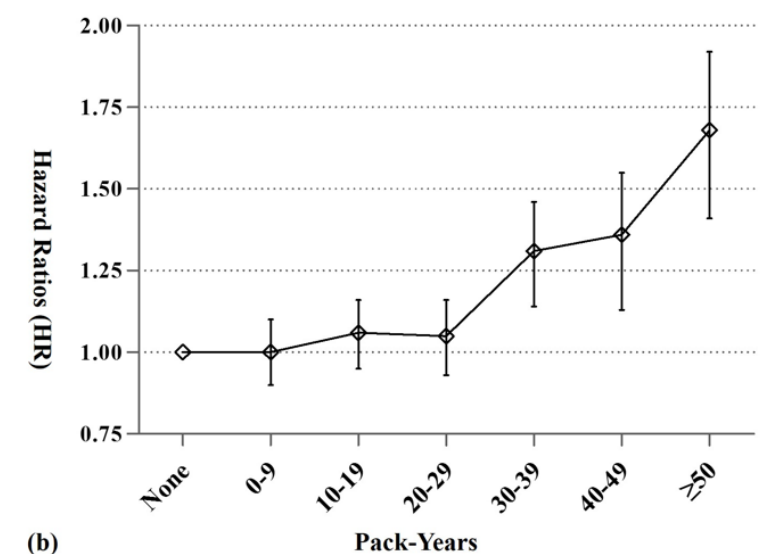

Figure 1. Incidence rates (a) and risk of developing (b) malignant glioma, according to cumulative amount of lifetime smoking. 


\subsection{Subgroup Analyses According to Age and Sex}

We analyzed subgroup according to age and sex in model 2. While current smokers older than 40 years had an increased risk of developing MG, younger current smokers less than 40 years showed no associations with developing MG (Table 4). Male smokers showed increased risks of developing MG, however, female smokers did not show any significant differences in developing MG compared to never smokers (Table 4).

Table 4. Subgroup analyses of risk of malignant glioma, according to age and sex.

\begin{tabular}{cccccc}
\hline Smoking Status & \multicolumn{1}{c}{ Age } & & \multicolumn{2}{c}{ Sex } \\
\hline & $20-39$ & $40-64$ & $\geq 65$ & Male & Female \\
\hline Never-smokers & 1 (reference) & 1 (reference) & 1 (reference) & 1 (reference) & 1 (reference) \\
\hline Former smokers & $1.20(0.93-1.55)$ & $1.03(0.92-1.17)$ & $0.92(0.78-1.06)$ & $1.03(0.94-1.13)$ & $0.85(0.60-1.21)$ \\
\hline Current smokers & $1.08(0.88-1.32)$ & $1.27(1.14-1.41)$ & $1.37(1.20-1.50)$ & $1.30(1.12-1.41)$ & $1.06(0.84-1.32)$ \\
\hline
\end{tabular}

All data are reported as hazard ratios with 95\% confidence intervals from adjusted model 2, which is adjusted for age, sex, alcohol consumption, body-mass index, income level, and exercise level.

\section{Discussion}

In this nationwide population-based cohort study, we examined the risk of developing MG according to current smoking status, the amount of cigarettes smoked per day, smoking duration, and the cumulative amount of smoking exposure over the lifetime. We counted newly diagnosed malignant gliomas among a large general population of Koreans $(9,811,768)$ from January 2009 to December 2017 and calculated the overall MG incidence rate: 8.56/100,000 person-years. This estimate is consistent with recent epidemiological glioma research [4,34]. We found a graded association between the cumulative amount of lifetime smoking and risk of MG among people who smoked $\geq 30$ pack-years.

To the best of our knowledge, this study included the largest number of glioma cases $(n=6100)$ among studies that evaluated the association between smoking and MG risk in adults. We were able to enroll a sufficiently large sample population ( 10 million people) with complete medical information, that was updated annually using the NHIS database from South Korea. This large and powerful database has already been validated by our previous studies [31-33,35]. Prior to this, the largest study was a case-control study including 4556 glioma cases [19], that investigated cigarette smoking and death from glioma, and found that smoking increased the risk of glioma death by $11 \%(\mathrm{OR}=1.11, \mathrm{CI}$ : 1.03-1.21). All previously published studies that evaluated potential associations between smoking and MG risk included fewer than 1000 glioma cases [21-24,26-30]. Among them, a cohort study including 89,935 Canadian women found an association between smoking and glioma incidence among women who smoked for more than 20 years (OR 1.51, CI 0.97-2.34), smoked more than 20 cigarettes per day (OR 1.44, CI 0.90-2.31), or smoked more than 15 pack-years (OR 1.50, CI 0.92-2.44); however, none of these trends were significant [28]. MG is a relatively rare disease, with incidence rates lower than $10 / 100,000$, thus, a very large population sample is needed to achieve meaningful statistical power. This could explain why most studies yielded negative results, while our study showed a prominent association between smoking and glioma risks.

We estimated the cumulative amount of lifetime smoking by calculating people's average pack-years, which is considered the most reliable parameter for analyzing the effects of smoking on the human body [11]. Using these data, we identified a graded association between the cumulative amount of lifetime smoking and MG risk for people who smoked 30 or more pack-years. The risk of developing MG increased in a dose-dependent manner, the more pack-years smoked ( $31 \%$ increase among people who ever smoked 30-39 pack-years, 36\% among people who ever smoked 40-49 pack years, $68 \%$ among people who ever smoked $>50$ pack-years). Unfortunately, we did not find a 
dose-dependent relationship between risk of MG and smoking duration, although current smokers had a significantly increased risk of MG, regardless of smoking duration. Moreover, former smokers who smoked less than 19 cigarettes per day or smoked for less than 29 years showed decreased risk compared with current and never smokers. This finding may suggest that cessation of smoking or reducing the amount of smoking per day could decrease the risk of developing MG like other types of cancer [34,36]. Further studies are needed to elucidate the effect of smoking cessation on glioma. Given our findings, physicians should consider discussing smoking cessation or reduction with their long-term heavy smokers during clinic appointments, to reduce their risk of developing MG.

Studies that have focused on pathophysiological mechanisms have provided prominent biological evidence of an association between smoking and glioma risk. A recent biological study including more than 2000 human tissues samples from various cancers showed multiple distinct mutational signatures induced by smoking, both in tissues directly exposed to smoking and tissues indirectly exposed to smoking [10]. Furthermore, nicotine, a major ingredient in cigarettes, was found to enhance the proliferation, migration, and radio-resistance of human malignant glioma cells [15]. Other recent studies showed that the blood-brain barrier, which is a unique anatomical structure that acts as a gatekeeper against hazardous agents, could be breached by cigarette smoking via the impairment of endothelial tight junctions $[16,37,38]$. Thus, smoking may facilitate various environmental carcinogens in penetrating the brain and damaging the brain $[7,10]$.

Our findings should be considered in light of several limitations. First, some data were acquired from self-reported questionnaires, which may introduce biases to our dataset. Second, although we considered many factors that potentially influenced the hazard ratios for the MG risk, several undefined factors were not included for adjustment. Third, although MG is comprised of heterogeneous subtypes, some of which are more frequent in the younger population than in the older population, analysis according to subtype was not possible in our study design. Further studies are needed to analyze the incidence and risk factors according to histologic and molecular subgroup of glioma. Fourth, we verified the accuracy of our methodology to identify gliomas by retrospectively reviewing electronic medical records at a tertiary referral hospital in Korea. However, these results from a tertiary hospital may not be generalizable to other hospitals in Korea. Lastly, we only found an association between smoking and risk of developing MG among the male patients in our sample. In contrast, previous studies found associations among female populations $[19,28,29]$. This discrepancy may be because the proportion of never-smokers in our female subset was $>94 \%$, which leaves a significantly lower proportion of female smokers to analyze compared with other female populations.

\section{Materials and Methods}

\subsection{Ethical Considerations}

This study was conducted in accordance with the ethical standards of the 1964 Declaration of Helsinki. The Institutional Review Board at our institution approved the study design (ethical code: KC18ZESI0648, permission date: 23 October 2018). To protect patients' private information, all individual data were anonymized. Owing to the retrospective nature of the study, the informed consent requirement was waived.

\subsection{Database Source}

This retrospective national-wide population-based study was performed using the National Health Insurance Service (NHIS) database from Korea, which is a mandatory health insurance system operated by the Korean government that covers almost $97 \%$ of Koreans (approximately 50 million people). The NHIS database includes medical information from each patient regarding demographics, clinical diagnoses, prescribed medications including chemotherapy, surgical procedures, and radiotherapy. Furthermore, through a routine national health examination that is provided by the NHIS, either for all enrolled adults $>40$ years old at least every two years, or for any workers at a company $>20$ years 
old, physical measurements, including height, weight, body-mass index (BMI), medical history, family history, social-behavioral history including cigarette smoking, alcohol consumption, and physical activity were obtained from self-reported questionnaire records.

\subsection{Study Population}

We reviewed the records from the NHIS database for all people who were $>20$ years old by 2009 . Because NHIS limits its database size to 10 million people due to the personal information protection act, 9,811,768 people were identified after excluding people with any cancer history and incomplete medical data. Among this dataset, a total of 6100 malignant gliomas were identified from January 2009 to December 2017. The mean follow-up periods for enrolled individuals were 7.31 years and 71,280,381 person-years. The overall flow for patient enrollment is illustrated in Figure 2.

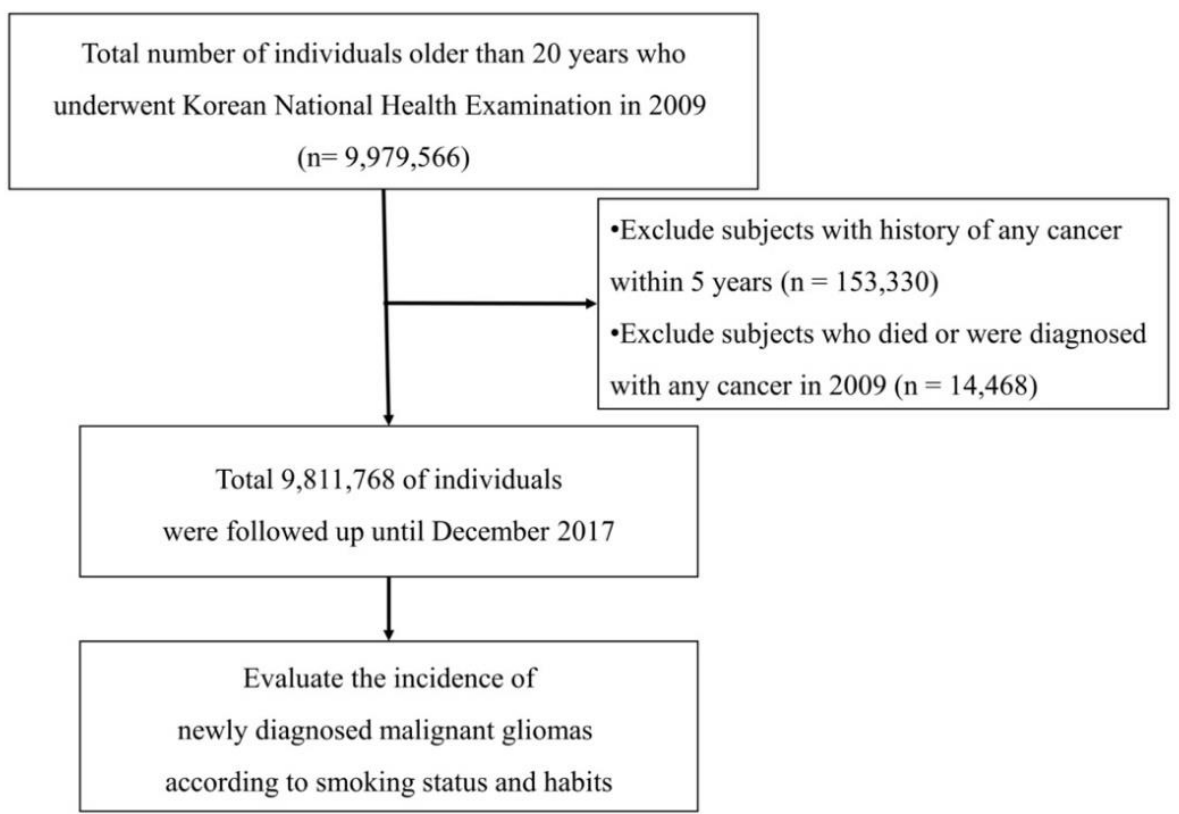

Figure 2. Flow of the study design.

\subsection{Definitions}

The medical code "C71" represents MG in the brain according to the International Classification of Disease, Tenth Revision (ICD-10), and includes all malignant gliomas, such as diffuse astrocytoma, anaplastic astrocytoma, ependymoma, anaplastic ependymoma, oligodendroglioma, anaplastic oligodendroglioma, and glioblastoma multiforme. Because all C71 patients received the additional cost coverage service from the NHIS for rare and incurable diseases, called the "benefit extension policy for rare incurable disease (BEP)", we defined MG for patients who were both diagnosed with C71 and registered into the benefit extension policy to ensure accurate categorization of the study population. To further verify the accuracy of our method to identify MG, we retrospectively reviewed the electronic medical records at Seoul St. Mary's Hospital, a tertiary referral hospital in Korea. After recruiting patients who visited this hospital between 2014 and 2018, we analyzed individual patient medical records for people who fit our definition of MG. We found a total of 220 patients who were radiologically or pathologically confirmed to have MG.

Smoking status was classified according to self-report questionnaire records. Current smokers were defined as people who smoked more than five packs (a total of 100 cigarettes) over their lifetime and continued to smoke; former smokers were defined as people who smoked more than five packs (a total of 100 cigarettes) over their lifetime, but who quit smoking prior to completing the questionnaire; and never-smokers were defined as people who had ever smoked five packs or fewer. The total duration 
of smoking years and the average daily number of cigarettes smoked (number of cigarettes per day) were included in the self-questionnaires. We calculated the cumulative amount of smoking exposure throughout lifetimes (i.e., pack-years) by multiplying the average per-day cigarette consumption by the smoking period. For alcohol consumption, heavy drinkers were defined as individuals who consumed an average of $\geq 30 \mathrm{~g}$ of alcohol per day. For physical activity, regular exercise was defined as intensive physical activity with faster-than-normal breathing for $\geq 20 \mathrm{~min}$ at a time more than three days per week, and moderate physical activity with slightly faster-than-normal breathing $\geq 30 \mathrm{~min}$ at least five days per week. Socio-economic status was classified based on yearly payments to the NHIS, according to income level.

\subsection{Statistical Analyses}

Data are expressed as means \pm standard deviations for continuous variables and as proportions for categorical variables. The one-way analysis of variance (ANOVA) test was used to compare differences between continuous variables, and the chi-square test was used to compare differences between categorical variables. The incidence rates for MG were calculated and expressed as the number of events per 100,000 person-years. We fit a model adjusted for the potential confounders of age and sex (model 1), and we fit another model that included the potential confounders from model 1 , but also included alcohol consumption, body-mass index, income level, and exercise level (model 2). The cumulative incidences rates for MG were compared between groups using the Kaplan-Meier method and the log-rank test. Cox proportional hazards models were used to analyze the adjusted risk of malignant glioma development, based on smoking status and daily amount or smoking duration; the results are expressed as hazard ratios (HR) with 95\% confidence intervals (CI). A $p$-value $<0.05$ was considered statistically significant. Statistical analyses were performed using SAS version 9.4 (SAS Institute, Cary, NC, USA).

\section{Conclusions}

This nationwide population-based study revealed that cigarette smoking may be significantly associated with an increased risk of developing MG. The MG incidence rate increased in proportion to the cumulative lifetime smoking amount among people who smoked more than 30 pack-years. Further prospective studies are needed to evaluate these associations, and preclinical studies should also be performed to define the biological mechanisms linking smoking and MG development in the brain, with focus on the unique anatomy of the blood-brain barrier.

Supplementary Materials: The following are available online at http:/www.mdpi.com/2072-6694/12/5/1343/s1, Table S1: Incidence rates and risk of malignant gliomas according to smoking status and age by decade.

Author Contributions: Conceptualization: S.H.Y.; Methodology: K.-D.H., Y.-M.P.; Software: K.-D.H.; Data Curation: K.-D.H.; Writing—Original Draft Preparation: S.A.; Writing—Review and Editing: S.H.Y., S.U.K.; Supervision: J.M.B., S.-S.J.; Funding Acquisition: S.A. All authors have read and agreed to the published version of the manuscript.

Funding: This research was supported by the Bio and Medical Technology Development Program of the National Research Foundation funded by the Ministry of Science and ICT in South Korea (NRF-2020M3A9E8024875).

Conflicts of Interest: The authors declare no conflicts of interest. The founding sponsors had no role in the design of the study; in the collection, analyses, or interpretation of data; in the writing of the manuscript, and in the decision to publish the results.

\section{References}

1. Wen, P.Y.; Kesari, S. Malignant gliomas in adults. N. Engl. J. Med. 2008, 359, 492-507. [CrossRef] [PubMed]

2. Lapointe, S.; Perry, A.; Butowski, N.A. Primary brain tumours in adults. Lancet 2018, 392, 432-446. [CrossRef]

3. Ostrom, Q.T.; Gittleman, H.; Truitt, G.; Boscia, A.; Kruchko, C.; Barnholtz-Sloan, J.S. CBTRUS statistical report: Primary brain and other central nervous system tumors diagnosed in the United States in 2011-2015. Neuro-Oncology 2018, 20, iv1-iv86. [CrossRef] [PubMed] 
4. Molinaro, A.M.; Taylor, J.W.; Wiencke, J.K.; Wrensch, M.R. Genetic and molecular epidemiology of adult diffuse glioma. Nat. Rev. Neurol. 2019, 15, 405-417. [CrossRef] [PubMed]

5. Stupp, R.; Mason, W.P.; Van Den Bent, M.J.; Weller, M.; Fisher, B.; Taphoorn, M.J.; Belanger, K.; Brandes, A.A.; Marosi, C.; Bogdahn, U. Radiotherapy plus concomitant and adjuvant temozolomide for glioblastoma. N. Engl. J. Med. 2005, 352, 987-996. [CrossRef] [PubMed]

6. Stupp, R.; Hegi, M.E.; Mason, W.P.; van den Bent, M.J.; Taphoorn, M.J.; Janzer, R.C.; Ludwin, S.K.; Allgeier, A.; Fisher, B.; Belanger, K. Effects of radiotherapy with concomitant and adjuvant temozolomide versus radiotherapy alone on survival in glioblastoma in a randomised phase III study: 5-year analysis of the EORTC-NCIC trial. Lancet Oncol. 2009, 10, 459-466. [CrossRef]

7. Hecht, S.S. Tobacco carcinogens, their biomarkers and tobacco-induced cancer. Nat. Rev. Cancer 2003, 3, 733. [CrossRef]

8. Jee, S.H.; Samet, J.M.; Ohrr, H.; Kim, J.H.; Kim, I.S. Smoking and cancer risk in Korean men and women. Cancer Causes Control 2004, 15, 341-348. [CrossRef]

9. Danaei, G.; Vander Hoorn, S.; Lopez, A.D.; Murray, C.J.; Ezzati, M.; Comparative Risk Assessment Collaborating Group. Causes of cancer in the world: Comparative risk assessment of nine behavioural and environmental risk factors. Lancet 2005, 366, 1784-1793. [CrossRef]

10. Alexandrov, L.B.; Ju, Y.S.; Haase, K.; Van Loo, P.; Martincorena, I.; Nik-Zainal, S.; Totoki, Y.; Fujimoto, A.; Nakagawa, H.; Shibata, T. Mutational signatures associated with tobacco smoking in human cancer. Science 2016, 354, 618-622. [CrossRef]

11. Peto, J. That the Effects of Smoking Should be Measured in Pack-Years: Misconceptions 4; Nature Publishing Group: Berlin, Germany, 2012.

12. Similä, T.; Virtanen, J.I. Association between smoking intensity and duration and tooth loss among Finnish middle-aged adults: The Northern Finland Birth Cohort 1966 Project. BMC Public Health 2015, 15, 1141. [CrossRef] [PubMed]

13. Ostrom, Q.T.; Fahmideh, M.A.; Cote, D.J.; Muskens, I.S.; Schraw, J.M.; Scheurer, M.E.; Bondy, M.L. Risk factors for childhood and adult primary brain tumors. Neuro-Oncology 2019, 21, 1357-1375. [CrossRef]

14. Ostrom, Q.T.; Bauchet, L.; Davis, F.G.; Deltour, I.; Fisher, J.L.; Langer, C.E.; Pekmezci, M.; Schwartzbaum, J.A.; Turner, M.C.; Walsh, K.M. The epidemiology of glioma in adults: A "state of the science" review. Neuro-Oncology 2014, 16, 896-913. [CrossRef] [PubMed]

15. Khalil, A.A.; Jameson, M.J.; Broaddus, W.C.; Lin, P.S.; Chung, T.D. Nicotine enhances proliferation, migration, and radioresistance of human malignant glioma cells through EGFR activation. Brain Tumor Pathol. 2013, 30, 73-83. [CrossRef] [PubMed]

16. Mazzone, P.; Tierney, W.; Hossain, M.; Puvenna, V.; Janigro, D.; Cucullo, L. Pathophysiological impact of cigarette smoke exposure on the cerebrovascular system with a focus on the blood-brain barrier: Expanding the awareness of smoking toxicity in an underappreciated area. Int. J. Environ. Res. Public Health 2010, 7, 4111-4126. [CrossRef] [PubMed]

17. Shao, C.; Zhao, W.; Qi, Z.; He, J. Smoking and glioma risk: Evidence from a meta-analysis of 25 observational studies. Medicine 2016, 95, e2447. [CrossRef]

18. Li, H.-X.; Peng, X.-X.; Zong, Q.; Zhang, K.; Wang, M.-X.; Liu, Y.-Z.; Han, G.-L. Cigarette smoking and risk of adult glioma: A meta-analysis of 24 observational studies involving more than 2.3 million individuals. OncoTargets Ther. 2016, 9, 3511.

19. Hou, L.; Jiang, J.; Liu, B.; Han, W.; Wu, Y.; Zou, X.; Nasca, P.C.; Xue, F.; Chen, Y.; Zhang, B. Smoking and adult glioma: A population-based case-control study in China. Neuro-Oncology 2015, 18, 105-113. [CrossRef]

20. Seliger, C.; Ricci, C.; Meier, C.R.; Bodmer, M.; Jick, S.S.; Bogdahn, U.; Hau, P.; Leitzmann, M.F. Diabetes, use of antidiabetic drugs, and the risk of glioma. Neuro-Oncology 2015, 18, 340-349. [CrossRef]

21. Vida, S.; Richardson, L.; Cardis, E.; Krewski, D.; McBride, M.; Parent, M.-E.; Abrahamowicz, M.; Leffondré, K.; Siemiatycki, J. Brain tumours and cigarette smoking: Analysis of the INTERPHONE Canada case-control study. Environ. Health 2014, 13, 55. [CrossRef]

22. Braganza, M.; Rajaraman, P.; Park, Y.; Inskip, P.; Freedman, N.; Hollenbeck, A.; De González, A.B.; Kitahara, C. Cigarette smoking, alcohol intake, and risk of glioma in the NIH-AARP Diet and Health Study. Br. J. Cancer 2014, 110, 242. [CrossRef] [PubMed] 
23. Lachance, D.H.; Yang, P.; Johnson, D.R.; Decker, P.A.; Kollmeyer, T.M.; McCoy, L.S.; Rice, T.; Xiao, Y.; Ali-Osman, F.; Wang, F. Associations of high-grade glioma with glioma risk alleles and histories of allergy and smoking. Am. J. Epidemiol. 2011, 174, 574-581. [CrossRef] [PubMed]

24. Cabaniols, C.; Giorgi, R.; Chinot, O.; Ferahta, N.; Spinelli, V.; Alla, P.; Barrie, M.; Lehucher-Michel, M.-P. Links between private habits, psychological stress and brain cancer: A case-control pilot study in France. J. Neuro-Oncol. 2011, 103, 307-316. [CrossRef] [PubMed]

25. Mandelzweig, L.; Novikov, I.; Sadetzki, S. Smoking and risk of glioma: A meta-analysis. Cancer Causes Control 2009, 20, 1927-1938. [CrossRef]

26. Benson, V.S.; Pirie, K.; Green, J.; Casabonne, D.; Beral, V. Lifestyle factors and primary glioma and meningioma tumours in the Million Women Study cohort. Br. J. Cancer 2008, 99, 185. [CrossRef]

27. Holick, C.N.; Giovannucci, E.L.; Rosner, B.; Stampfer, M.J.; Michaud, D.S. Prospective study of cigarette smoking and adult glioma: Dosage, duration, and latency. Neuro-Oncology 2007, 9, 326-334. [CrossRef]

28. Silvera, S.A.N.; Miller, A.B.; Rohan, T.E. Cigarette smoking and risk of glioma: A prospective cohort study. Int. J. Cancer 2006, 118, 1848-1851. [CrossRef]

29. Efird, J.T.; Friedman, G.D.; Sidney, S.; Klatsky, A.; Habel, L.A.; Udaltsova, N.V.; Van Den Eeden, S.; Nelson, L.M. The risk for malignant primary adult-onset glioma in a large, multiethnic, managed-care cohort: Cigarette smoking and other lifestyle behaviors. J. Neuro-Oncol. 2004, 68, 57-69. [CrossRef]

30. Zheng, T.; Cantor, K.P.; Zhang, Y.; Chiu, B.C.; Lynch, C.F. Risk of brain glioma not associated with cigarette smoking or use of other tobacco products in Iowa. Cancer Epidemiol. Prev. Biomark. 2001, 10, 413-414.

31. Park, S.; Chun, J.; Han, K.-D.; Soh, H.; Kang, E.A.; Lee, H.J.; Im, J.P.; Kim, J.S. Dose-response relationship between cigarette smoking and risk of ulcerative colitis: A nationwide population-based study. J. Gastroenterol. 2019, 54, 881-890. [CrossRef]

32. Park, J.-H.; Kim, D.-H.; Park, Y.-G.; Kwon, D.-Y.; Choi, M.; Jung, J.-H.; Han, K. Cancer risk in patients with Parkinson's disease in South Korea: A nationwide, population-based cohort study. Eur. J. Cancer 2019, 117, 5-13. [CrossRef] [PubMed]

33. Lee, Y.B.; Lee, J.H.; Lee, S.Y.; Lee, J.H.; Yu, D.S.; Han, K.D.; Park, Y.G. Association between smoking and Behçet's disease: A nationwide population-based study in Korea. J. Eur. Acad. Dermatol. Venereol. 2019, 33, 2114-2122. [CrossRef] [PubMed]

34. Choi, S.; Chang, J.; Kim, K.; Park, S.M.; Lee, K. Effect of smoking cessation and reduction on the risk of cancer in Korean men: A population based study. Cancer Res. Treat. Off. J. Korean Cancer Assoc. 2018, 50, 1114. [CrossRef] [PubMed]

35. Lee, E.J.; Do Han, K.; Han, J.H.; Lee, J.H. Smoking and risk of psoriasis: A nationwide cohort study. J. Am. Acad. Dermatol. 2017, 77, 573-575. [CrossRef] [PubMed]

36. Godtfredsen, N.S.; Prescott, E.; Osler, M. Effect of smoking reduction on lung cancer risk. Jama 2005, 294, 1505-1510. [CrossRef]

37. Abbruscato, T.J.; Lopez, S.P.; Roder, K.; Paulson, J.R. Regulation of blood-brain barrier Na, K, 2Cl-cotransporter through phosphorylation during in vitro stroke conditions and nicotine exposure. J. Pharmacol. Exp. Ther. 2004, 310, 459-468. [CrossRef]

38. Abbruscato, T.J.; Lopez, S.P.; Mark, K.S.; Hawkins, B.T.; Davis, T.P. Nicotine and cotinine modulate cerebral microvascular permeability and protein expression of ZO-1 through nicotinic acetylcholine receptors expressed on brain endothelial cells. J. Pharm. Sci. 2002, 91, 2525-2538. [CrossRef]

(C) 2020 by the authors. Licensee MDPI, Basel, Switzerland. This article is an open access article distributed under the terms and conditions of the Creative Commons Attribution (CC BY) license (http://creativecommons.org/licenses/by/4.0/). 